\title{
Titanocene-Catalyzed Reaction of Alkenes and Dienes with Alkyl Halides and Chlorosilanes
}

\author{
Jun Terao and Nobuaki Kambe* \\ Department of Applied Chemistry, Faculty of Engineering, Osaka University,
}

Received July 19, 2001

\begin{abstract}
New catalytic reactions for regioselective introduction of alkyl and/or silyl functionalities to alkenes and dienes are described. These reactions proceed efficiently under mild conditions by the use of $\mathrm{Cp}_{2} \mathrm{TiCl}_{2}$ as a catalyst in the presence of Grignard reagents. The present study would provide a prototype for the practical use of alkyl halides and chlorosilanes in transition metal-catalyzed reactions. In these reactions, ate complexes of titanocene play important roles as the active species. The scope and limitations, as well as reaction pathways, are discussed.
\end{abstract}

\section{Introduction}

Introduction of carbon ${ }^{1}$ and/or silicon ${ }^{2}$ functional groups across carbon-carbon unsaturated bonds constitutes important processes in organic syntheses. There have been developed a number of catalytic reactions applicable to such transformations, wherein late transition metals have been employed as the catalysts in many cases. Recently, we have accomplished unprecedented alkylation ${ }^{3}$ and silylation ${ }^{4}$ reactions of alkenes using $\mathrm{Cp}_{2} \mathrm{ZrCl}_{2}$ as a catalyst in the presence of ${ }^{\mathrm{n}} \mathrm{BuMgCl}$. These successful results prompted us to examine the chemical behavior of $\mathrm{Cp}_{2} \mathrm{TiCl}_{2}{ }^{5}$ leading to development of several unique reactions. In this article, we describe a new type of titanocene-catalyzed reaction ${ }^{6}$ of alkenes and dienes with alkyl halides and/or chlorosilanes, where regioselective $\mathrm{C}-\mathrm{C}$ and/or $\mathrm{C}-\mathrm{Si}$ bond forming steps are involved.

\section{Regioselective Double-Alkylation of Alkenes ${ }^{7}$}

Recently, we have developed a unique double-alkylation reaction of aryl alkenes with alkyl bromides using a titanocene catalyst as shown in eq 1 .

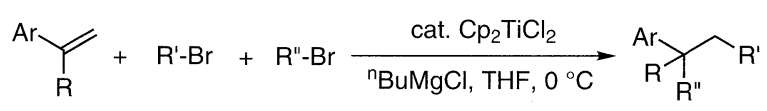

For example, to a mixture of styrene, 1-bromopentane (1.1 equiv), tert-butyl bromide (1.1 equiv) and $\mathrm{Cp}_{2} \mathrm{TiCl}_{2}(0.05$ equiv) was added a THF solution of ${ }^{n} \mathrm{BuMgCl}$ ( 2.2 equiv) at $0{ }^{\circ} \mathrm{C}$, and the solution was stirred for $1 \mathrm{~h}$. The double-alkylation product 1 was obtained in $88 \%$ yield in which pentyl and tert-butyl groups are incorporated regioselectively at the adjacent carbons (Table 1, run 1). The combined use of secondary and primary alkyl bromides (runs 2, 3) or tertiary and secondary alkyl bromides (run 4) afforded the corresponding double-alkylated products $\mathbf{2}-\mathbf{4}$. Chloro substituents were not affected in this reaction system and the desired product 5 was obtained in good yield (run 5). The same alkyl groups can be introduced at both vicinal carbons when only one alkyl bromide was used. For example, the corresponding products were obtained in good yields by the use of 2.2 equiv of primary or secondary alkyl halides (runs 6-9). Under similar conditions internal alkenes, such as $\beta$-methyl styrene or stilbene, and 1-alkenes having no aryl group, such as 1-octene or 3-ethyl-1-butene were sluggish. This chemoselectivity allows the successful synthesis of diene 10 in $80 \%$ yield, using 5-bromo-1-pentene (run 10). Interestingly, when excess amount of 1,3-dibromopropane or 1,4-dibromobutane was used, products $\mathbf{1 1 a}, \mathbf{b}$ containing 5or 6-membered ring were obtained in moderate yields (eq 2).

Table 1. Ti-Catalyzed double alkylation of aryl alkenes

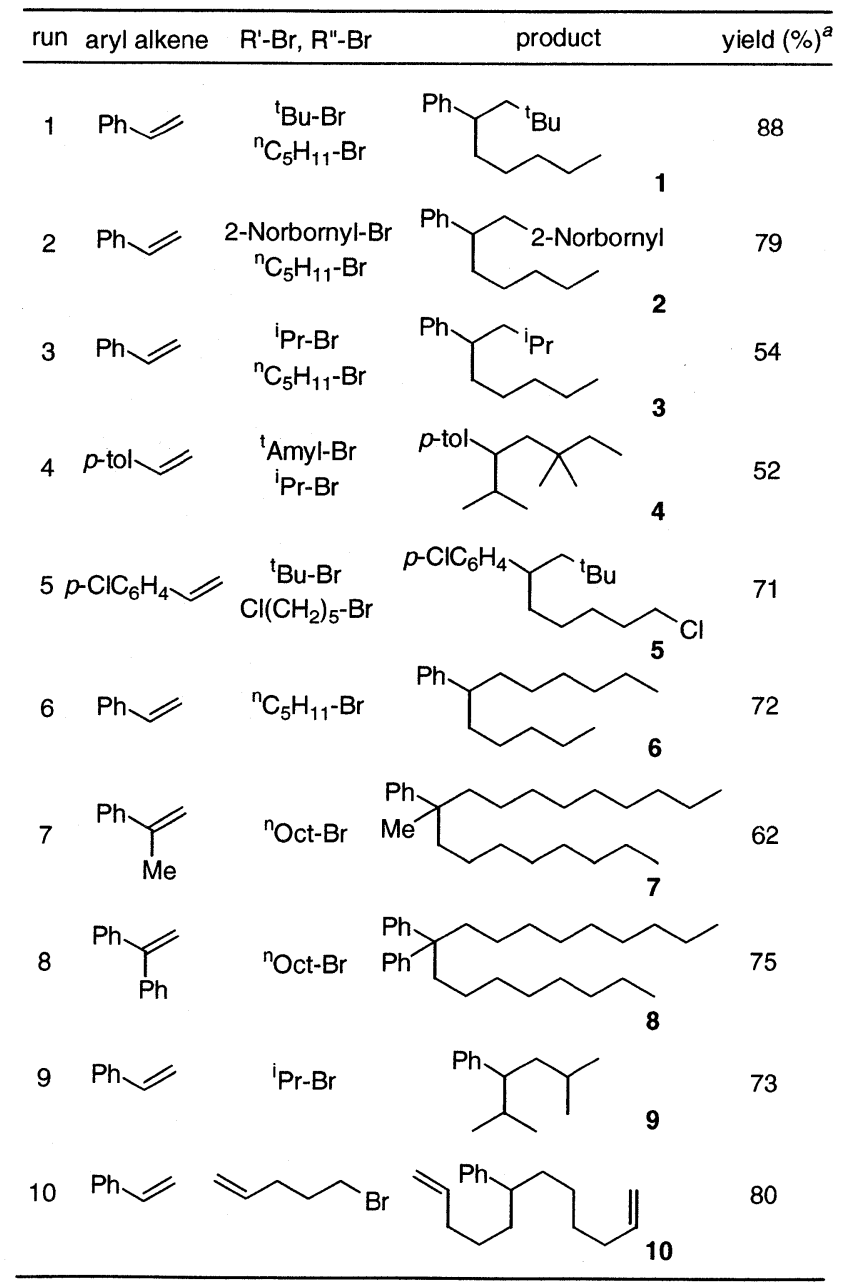

${ }^{a}$ Isolated yield. 


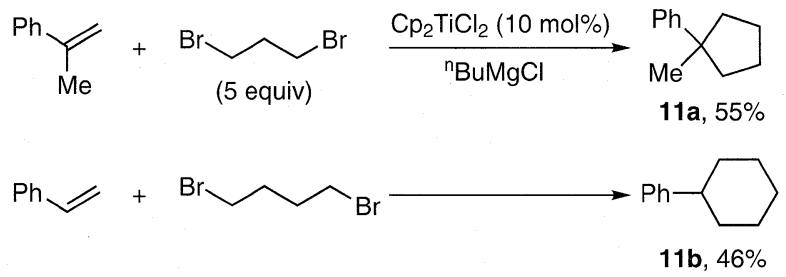

A plausible reaction pathway is shown in Scheme 1 . Titanocene dichloride reacts with ${ }^{\mathrm{n}} \mathrm{BuMgCl}$ to generate dibutyltitanate(III) complex 13a via $\mathrm{Cp}_{2} \mathrm{TiCl}^{8}$ and butyltitanocene $\mathbf{1 2}^{9}$. One electron transfer from 13a to alkyl bromides leads to cleavage of the $\mathrm{C}-\mathrm{Br}$ bond to give an alkyl radical $^{10}$ along with dibutyltitanocene 14 , which readily forms $\mathrm{Cp}_{2} \mathrm{Ti}(\mathbf{1 5})$ via $\beta$-hydrogen elimination ${ }^{11}$. Addition of the thus-formed alkyl radical to styrene at the terminal carbon affords a benzyl radical species, which recombines with 15 to give the corresponding benzyltitanium complex 16. Subsequent transmetalation ${ }^{12}$ of $\mathbf{1 6}$ with ${ }^{\mathrm{n}} \mathrm{BuMgCl}$ gives the corresponding benzyl Grignard reagent $\mathbf{1 7}$ along with regeneration of 12. The double-alkylated products are formed by the reaction of $\mathbf{1 7}$ with alkyl bromides.

Scheme 1

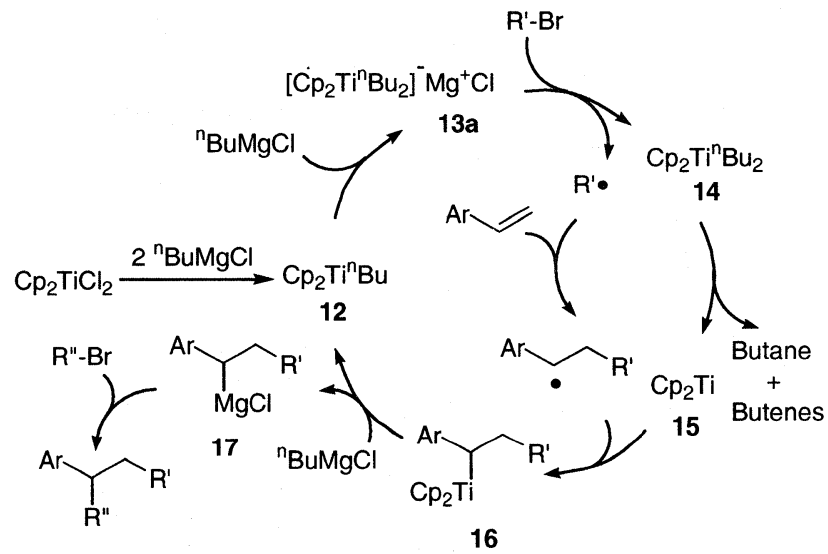

Since it is known that $\mathrm{Cp}_{2} \mathrm{TiCl}_{2}$ catalyzes hydromagnesation $^{13}$ of styrene to give benzylmagnesium halide by the use of ${ }^{\mathrm{i}} \mathrm{PrMgX}$ in the absence of alkyl halides, we tested whether this hydromagnesiation can take place in the present reaction. When we carried out a reaction of styrene with octyl bromide using ${ }^{\mathrm{i}} \mathrm{PrMgCl}$ instead of ${ }^{\mathrm{n}} \mathrm{BuMgCl}$, the reduction of octyl bromide ${ }^{14}$ predominated and only a trace amount of the double-alkylated product $(<2 \%)$ was obtained. In this reaction, hydromagnesiation was completely suppressed. The fact that $\mathrm{Cp}_{2} \mathrm{TiCl}_{2}$ reacts with Grignard reagents $(\mathrm{RMgX})$ to form anionic $\mathrm{Ti}$ (III) ate complexes $\left[\mathrm{Cp}_{2} \mathrm{TiR}_{2}\right]^{-} \mathrm{MgX}^{+}$and that $\left[\mathrm{Cp}_{2} \mathrm{Ti}^{\mathrm{i}} \mathrm{Pr}_{2}\right]^{-} \mathrm{MgX}^{+}$is unstable at temperatures above $-50{ }^{\circ} \mathrm{C}$ yielding hydride complexes whereas $\left[\mathrm{Cp}_{2} \mathrm{TiEt}_{2}\right]^{-} \mathrm{MgX}^{+}$is stable at room temperature ${ }^{15}$, may support that an ate complex $\left[\mathrm{Cp}_{2} \mathrm{Ti}^{\mathrm{n}} \mathrm{Bu}_{2}\right]^{-} \mathrm{MgCl}^{+}$has enough life time to play an important role as the active species for the electron transfer to alkyl halides in our reaction. Then, we examined the intermediary of $\left[\mathrm{Cp}_{2} \mathrm{Ti}^{\mathrm{n}} \mathrm{Bu}_{2}\right]^{-} \mathrm{MgCl}^{+}$as follows. $\mathrm{Cp}_{2} \mathrm{TiCl}_{2}(0.025 \mathrm{M})$ was treated with a large excess of ${ }^{\mathrm{n}} \mathrm{BuMgCl}(0.9 \mathrm{M})$ at $0{ }^{\circ} \mathrm{C}$ in THF. The ESR spectrum of the resulting dark-brown solution showed a quintet hyperfine splitting at $g=1.989$ with a coupling constant of 2.4 gauss which might be ascribable to the coupling with the four equivalent $\alpha$-hydrogens of the two butyl groups of 13a. This is quite similar to the ESR spectrum of $\left[\mathrm{Cp}_{2} \mathrm{TiEt}_{2}\right]^{-} \mathrm{MgCl}^{+}$( $g=1.991,2.3$ gauss) generated by the reaction of $\mathrm{Cp}_{2} \mathrm{TiCl}_{2}$ with $\mathrm{EtMgCl}^{15 \mathrm{a}}$. Addition of cyclohexyl bromide into the THF solution of 13a quickly changed the color to green and the ESR signal disappeared. This result is in accord with the SET process in Scheme 1 (13a to 14).

In order to confirm the radical mechanism for the carboncarbon bond forming step in Scheme 1, we carried out the reaction of styrene using (bromomethyl)cyclopropane as the alkylating reagent. As might be expected, cyclopropylmethyl and 3-butenyl units were introduced regioselectively giving rise to $\mathbf{1 8}$ as the sole double-alkylation product in $50 \%$ yield (eq 3). This result can be explained by the evidence that the rate constant of the ring-opening of the cyclopropylmethyl radical, $k=1.3 \times 10^{8} \mathrm{~s}^{-1}$ at $25{ }^{\circ} \mathrm{C}^{16}$, is much faster than the addition of primary radicals to styrene, $k=5.4 \times 10^{4} \mathrm{M}^{-1} \mathrm{~s}^{-1}$ at $25{ }^{\circ} \mathrm{C}^{17}$.

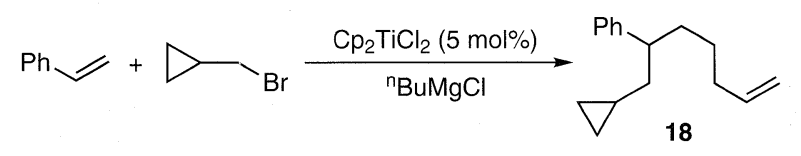

The intermediary of benzylmagnesium chlorides in the second alkylation step is supported by the following results. The reaction of styrene with 1.5 equiv of 2-norbornyl bromide was conducted at $0{ }^{\circ} \mathrm{C}$ for $1 \mathrm{~h}$ using 2.2 equiv of ${ }^{\mathrm{n}} \mathrm{BuMg}$ $\mathrm{Cl}$ in the presence of $5 \mathrm{~mol} \%$ of $\mathrm{Cp}_{2} \mathrm{TiCl}_{2}$. Quenching the reaction mixture with $\mathrm{D}_{2} \mathrm{O}$ afforded the mono-alkylated compound 19 which contained a deuterium at the benzylic position $(d$-content $>95 \%)$ in $59 \%$ yield (eq 4$)$. This result suggests that a benzylmagnesium chloride $\mathbf{2 0}$ was formed in this reaction. While $\mathbf{2 0}$ could not be trapped efficiently with 2-norbornylbromide in this reaction, probably due to steric reasons, sterically non-encumbered primary and secondary alkyl bromides react smoothly with $\alpha$-substituted benzylmagnesium chlorides under the reaction conditions employed. For example, the reaction of $21^{18}(0.36 \mathrm{M})$ with isopropyl bromide (1.5 equiv) in THF at $0{ }^{\circ} \mathrm{C}$ afforded 9 in $62 \%$ yield after only $10 \min ^{19}$. Moreover, when we performed a similar reaction using ${ }^{i} \mathrm{PrBr}$ as an alkylating reagent instead of 2-norbornyl bromide, the mono-alkylated product was not detected, resulting in the formation of a double-alkylated compound as the sole product due to the rapid reaction of ${ }^{\mathrm{i}} \mathrm{PrBr}$ with the benzylmagnesium intermediate generated in situ.

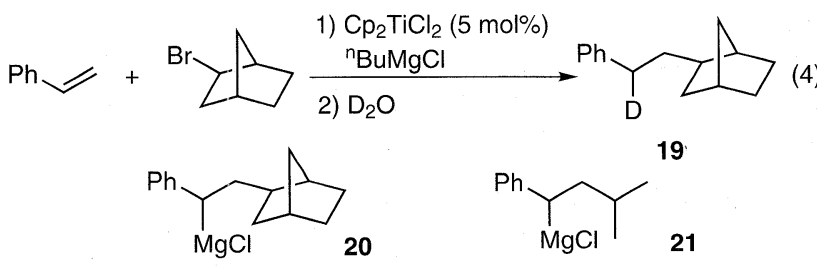

3. Titanocene-Catalyzed Alkylation of Aryl Alkenes Using Alkyl Halides: a Mizoroki-Heck type transformation ${ }^{20}$

Titanocene-catalyzed addition of two alkyl groups to car- 
bon-carbon double bonds was shown in the previous section (eq 1). It is very surprising that changing the solvent from THF to ether led to the formation of different products as shown in eq 5 , in which a terminal vinylic hydrogen was replaced with an alkyl group. This reaction provides formally the same transformation as the Mizoroki-Heck reaction which has widely been applied to the preparation of substituted alkenes ${ }^{21}$. This reaction proceeds efficiently in the presence of a palladium catalyst using aryl, 1-alkenyl, benzyl, allyl, and 1-alkynyl halides; however, alkyl halides having $\beta$-hydrogens can not be employed in this reaction due to the facile $\beta$-hydrogen elimination from the $\sigma$-alkylpalladium intermediates $^{22}$. Our Ti-catalyzed reaction (eq 5) might be a supplementary procedure to this well-known reaction since alkyl groups can be introduced using alkyl halides at the terminal vinylic carbon of alkenes with perfect regioselectivity. The same transformation has been achieved by cobalt ${ }^{23 a}$ or nickel $^{23 b}$ catalyst.

$$
\mathrm{Ar}=+\underset{(X=\mathrm{Br}, \mathrm{Cl})}{\mathrm{R}^{\prime}-\mathrm{X}} \frac{\text { cat. } \mathrm{Cp}_{2} \mathrm{TiCl}_{2}}{\mathrm{Et}_{2} \mathrm{O},{ }^{\mathrm{n}} \mathrm{BuMgCl}, 0^{\circ} \mathrm{C}} \mathrm{Ar} / \mathrm{R}^{\prime}
$$

When an ether solution of 1-bromodecane, styrene (3.0 equiv), ${ }^{\mathrm{n}} \mathrm{BuMgCl}$ ( 1.3 equiv) and a catalytic amount of $\mathrm{Cp}_{2} \mathrm{TiCl}_{2}$ (0.03 equiv) was stirred for $2.5 \mathrm{~h}$ at $0{ }^{\circ} \mathrm{C}$ under nitrogen, $(E)-1$-phenyl-1-dodecene 22 was obtained in $63 \%$ yield based on alkyl bromide with $>98 \%$ regio- and stereoselectivities (Table 2, run 1). The use of one equivalent of styrene reduced the yield of $\mathbf{2 2}$ to $37 \%$ and increased the formation of decane and 1 -decene in $25 \%$ and $18 \%$ yields, respectively. The use of primary bromides (runs 2-6) afforded the corresponding products 23-27. When cyclohexyl bromide was used as the alkylating reagent, 28 was obtained in moderate yield under the same conditions $(46 \%$ based on the halide), but the yield of $\mathbf{2 8}$ was improved to $71 \%$ based on styrene by employing $20 \mathrm{~mol} \%$ of a titanocene catalyst and 1.5 equivalent of cyclohexyl bromide (run 7). It should be noted that this reaction also proceeded with secondary alkyl chlorides to give $\mathbf{2 8}$ and $\mathbf{2 9}$.

A plausible pathway of this alkylation is shown in Scheme 2. In ether solution, the electron transfer from titanate(III) complex 13b to alkyl halides took place predominantly along with the formation of $\mathbf{3 0}$ over the transmetalation leading to benzylmagnesium 17 and 12. This different behavior of $\mathbf{1 3 b}$ might be explained by assuming that elimination of benzylmagnesium $\mathbf{1 7}$ from $\mathbf{1 3 b}$ is an equilibrium process and that $\mathbf{1 7}$ can react with alkyl halides to give double-alkylation products only in a strongly coordinating solvent such as THF. In ether, 17 recombines with $\mathrm{Cp}_{2} \mathrm{Ti}^{\mathrm{n}} \mathrm{Bu}$ to regenerate $\mathbf{1 3 b}$, which transfers an electron to alkyl halides to give 30. The successive $\beta$-elimination via site selective hydrogen abstraction at the benzylic group of $\mathbf{3 0}$ affords the corresponding product and $\mathbf{1 5 .}$

\section{Carbosilylation of Alkenes and Dienes ${ }^{24}$}

Addition of a carbon and a silicon unit to carbon-carbon unsaturated bonds (carbosilylation) is a synthetically very useful reaction for synthesis of a variety of organosilicon compounds with concomitant construction of the desired carbon skeletons. There have already been developed several
Table 2. Ti-Catalyzed alkylation of aryl alkenes with alkyl halides

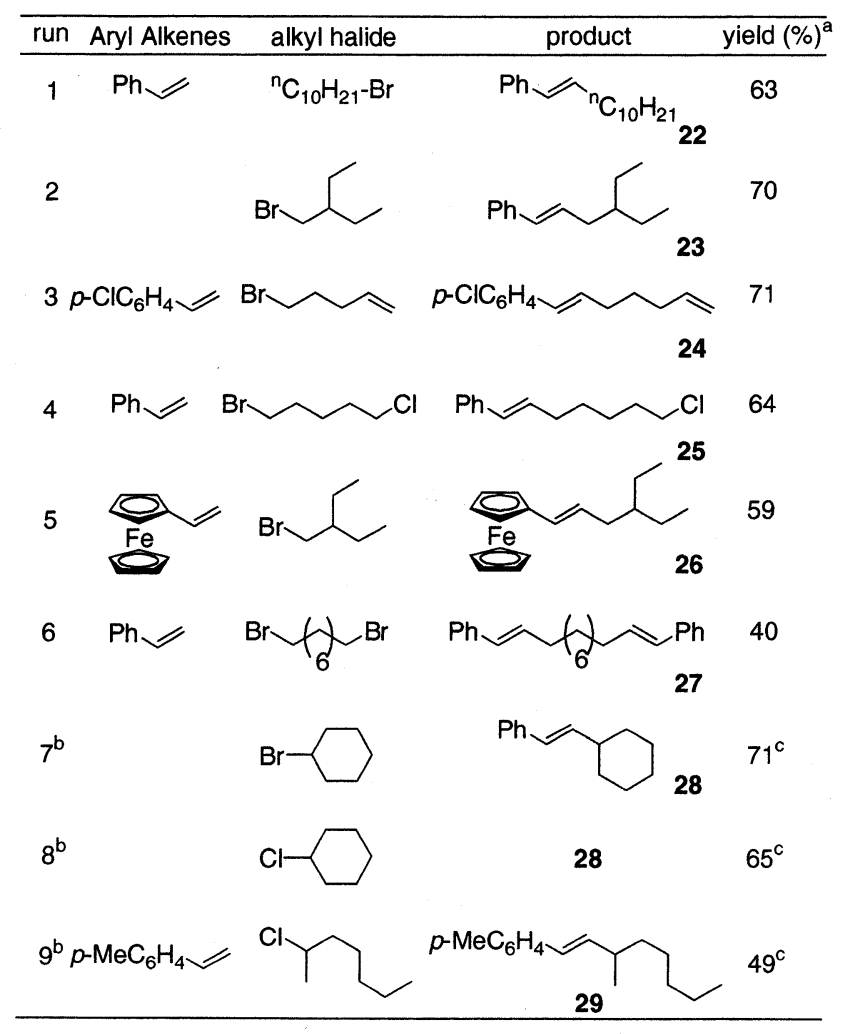

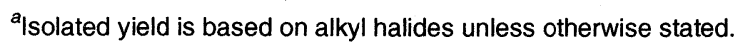

${ }^{b}$ Secondary alkyl halides ( 1.5 equiv) and titanocene catalyst (20 mol \%) were used. 'Based on styrene used.

Scheme 2

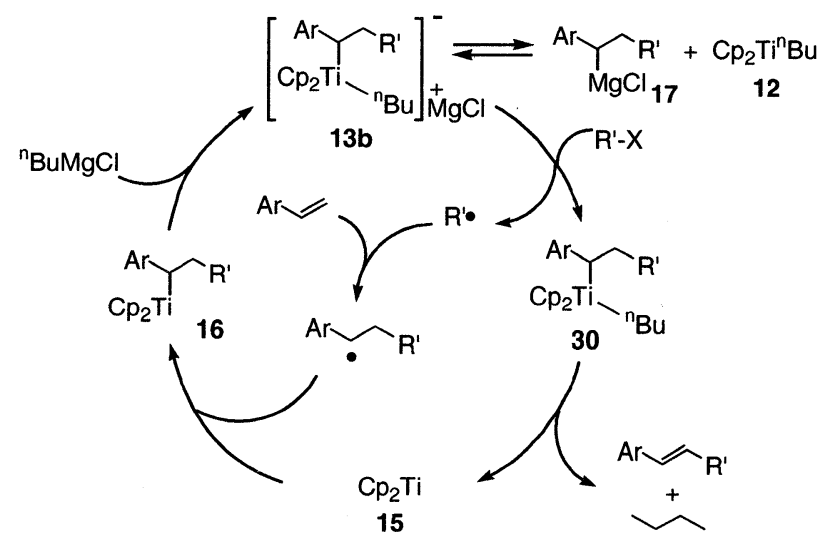

methods for the carbosilylation of alkynes ${ }^{25}$, dienes ${ }^{26}$ and allenes ${ }^{27}$. By the use of $\mathrm{Cp}_{2} \mathrm{TiCl}_{2}$, we have developed a new catalytic system for carbosilylation of alkenes by the combined use of alkyl halides and chlorosilanes (eq 6). This reaction can also be applied to dienes successfully (eq 7) and the results are summarized in Table 3.

$$
\begin{aligned}
& \mathrm{R} V+\mathrm{R}^{\prime}-\mathrm{X}+\mathrm{R}_{3}{ }_{3} \mathrm{Si}-\mathrm{Cl} \underset{{ }^{\mathrm{BuMgCl}}}{\stackrel{\text { cat. } \mathrm{Cp}_{2} \mathrm{TiCl}_{2}}{\longrightarrow}} \mathrm{R}_{\mathrm{SiR}_{3}{ }_{3}}^{\mathrm{R}} \\
& \mathrm{R}^{\prime} \sim \mathrm{SiR}_{3}{ }_{3}(7)
\end{aligned}
$$


When the reaction of styrene with 1.1 equiv of chlorotriethylsilane and tert-butyl bromide was carried out at $0{ }^{\circ} \mathrm{C}$ in THF, high yield of carbosilylation product 31 was obtained as a single regioisomer, possessing a tert-butyl group at the terminal carbon and a triethylsilyl group at the benzylic carbon (run 1). In this reaction, a trace amount $(<1 \%)$ of $\mathrm{Et}_{3} \mathrm{Si}^{\mathrm{n}} \mathrm{Bu}$ was formed by the direct reaction of $\mathrm{Et}_{3} \mathrm{SiCl}$ with ${ }^{\mathrm{n}} \mathrm{BuMgCl}$. As shown in runs 2, 5, 6, 10 and 11, this reaction proceeds when secondary bromides are used. Primary alkyl bromides can also be employed as the alkylating reagents, but the reaction is somewhat less efficient due to the formation of a double-alkylated compound as a byproduct (run 3). When chloro substituted substrates were used, the reaction took place site selectively at the bromo functional group leaving the chloro substituents intact, giving rise to 34 in $40 \%$ yield (run 4). In addition to aryl substituted alkenes, a vinylsilane underwent carbosilylation to give the corresponding gem-disilyl product $\mathbf{3 6}$ in a moderate yield (run 6).

When 2,3-dimethyl-1, 3-butadiene was treated with tertbutyl bromide and $\mathrm{Et}_{3} \mathrm{SiCl}$ under identical conditions, alkyl and silyl units are introduced at the 1- and 4-positions forming 37 in high yield with an $E / Z$ ratio of $96 / 4$ (run 7). It should be noted that secondary and tertiary alkyl chlorides can be employed as suitable alkylating reagents in this reaction giving 37 and 38 in good yields (runs 8, 9). Phenyl and benzyl substituted 1,3-butadienes also gave the corresponding products in good yields (runs 10-12).

The present carbosilylation would proceed via a similar pathway as double-alkylation, i.e., the addition of alkyl radicals toward alkenes or dienes in the carbon-carbon bond forming step and an electrophilic trapping of benzyl- or allylmagnesium halides with chlorosilanes in the carbon-silicon bond forming step. A plausible pathway of this reaction is outlined in Scheme 3 for the case of dienes.

When the reaction of 6-bromo-1-phenyl-1-hexene with $\mathrm{Me}_{3} \mathrm{SiCl}$ was performed under identical conditions, only the cyclized product $\mathbf{4 2}$ was obtained probably via 5-exo radical cyclization (eq 8). This result strongly supports a radical mechanism for the carbon-carbon forming process.

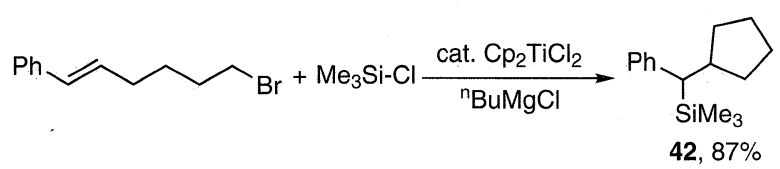

In order to prove the active species of the silylation step, allyltitanocene complex $\mathbf{4 3}$ was prepared by the reported procedure $^{28}$, and its reactivity toward chlorosilanes was examined. When a THF solution of $\mathbf{4 3}$ and $\mathrm{Et}_{3} \mathrm{SiCl}$ (1 equiv) was stirred at $0{ }^{\circ} \mathrm{C}$ for $1 \mathrm{~h}$, no reaction took place. On the other hand, 44 was formed in 73\% yield when a similar reaction was performed in the presence of a stoichiometric amount of ${ }^{\mathrm{n}} \mathrm{BuMgCl}$ (eq 9). These results suggest that chlorosilane reacts with the ate complex $\mathbf{4 5}$ or with allylmagnesium chloride 46 which is formed by transmetalation from 43 via 45 . Although a possibility that titanate complexes such as $\mathbf{4 5}$ react directly with chlorosilanes cannot be ruled out, the results of the next section support that the transmetalation does proceed under the conditions employed.
Table 3. Ti-Catalyzed carbosilylation of alkenes or dienes

run alkene or diene

${ }^{a}$ Isolated yield. ${ }^{b} \mathrm{NMIR}$ yield.

Scheme 3

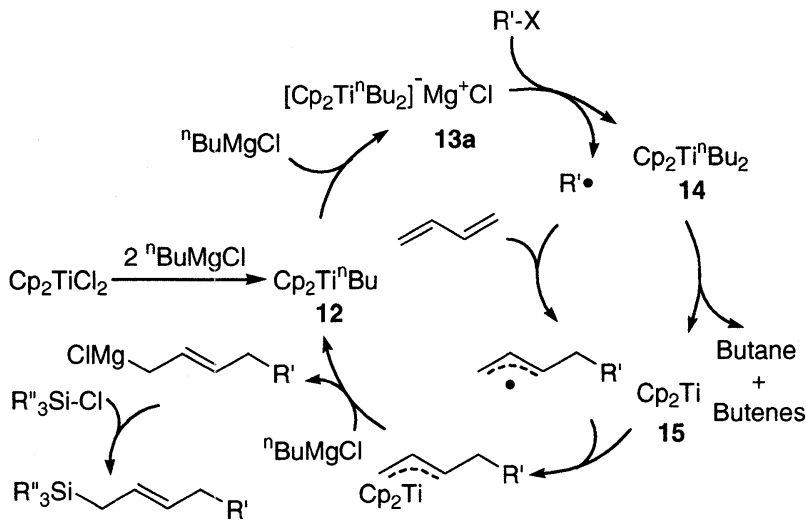




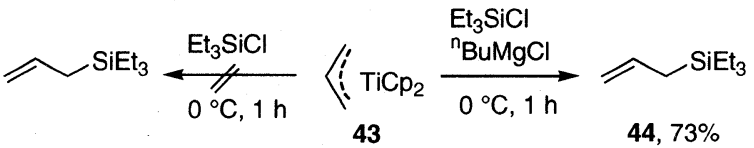

$$
\begin{aligned}
& {\left[\underset{\substack{\mathrm{Bu} \\
\mathrm{n}}}{\mathrm{TiCp}_{\mathrm{Bu}}}\right]_{\mathrm{MgCl}}^{-} \underset{\mathrm{MgCl}}{+}}
\end{aligned}
$$

\section{Carbomagnesation of Alkenes and Dienes ${ }^{29}$}

We then attempted carbomagnesation by using $\mathrm{Cp}_{2} \mathrm{TiCl}_{2}$ as the catalyst. A typical example is as follows. To a mixture of 2, 3-dimethyl-1, 3-butadiene, tert-amyl chloride (2.0 equiv), and $5 \mathrm{~mol} \%$ of $\mathrm{Cp}_{2} \mathrm{TiCl}_{2}$ was added to a THF solution of ${ }^{\mathrm{n}} \mathrm{BuMgCl}$ (3.1 equiv) at $0{ }^{\circ} \mathrm{C}$, and the solution was stirred for $2 \mathrm{~h}$. Quenching the reaction mixture with $\mathrm{D}_{2} \mathrm{O}$ afforded mono-alkylated compounds $4 \mathbf{4 a}$ and $\mathbf{4 7}$ b containing a deuterium at one of the two allylic positions in $94 \%$ total yield as a mixture of regioisomers $(\mathbf{4 7} \mathbf{a} / \mathbf{4 7} \mathbf{b}=35 / 65)(\mathrm{eq} 10)$. When the reaction was quenched with benzoyl chloride instead of $\mathrm{D}_{2} \mathrm{O}$, the acylated product 49 was obtained in $92 \%$ yield as a single regioisomer (Table 4, run 1). These results suggest the formation of allyl Grignard reagent 48.

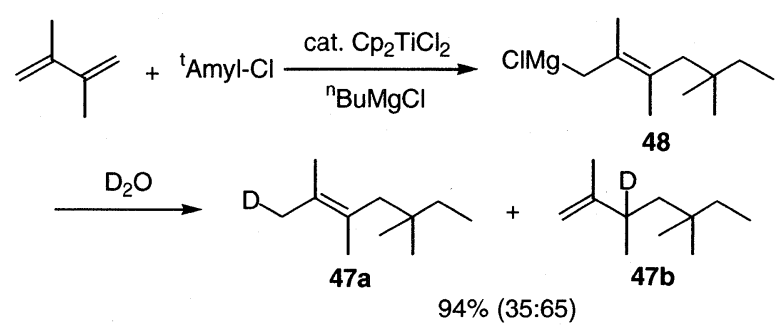

Table 4 shows some representative results of carbomagnesation using various substrates and electrophiles performed in a similar one-pot sequence. When stannyl chloride was used as an electrophile, stannylation took place regioselectively at the terminal position of the allylmagnesium intermediates due to the steric hindrance of the stannyl group (run 2). Secondary alkyl bromides can also be employed as suitable alkylating reagents (runs 3,8 ). On the other hands, $n$-octyl bromide gave the desired product only in poor yield, resulting in the formation of a double-alkylated product probably due to the rapid reaction of primary bromide with allylmagnesium chloride generated in situ. This can be supported by the evidence that a sterically hindered primary bromide can be employed as a suitable alkylating reagent (run 4). As for the scope of dienes, phenyl and benzyl substituted 1,3-butadienes and 1,3-cyclohexadiene afforded the corresponding products in good yields (runs 3, 5 and 6). 1, 1-Diphenylethylene underwent carbomagnesation in the presence of tert$\mathrm{BuCl}$ under similar conditions to afford a mono-alkylated product possessing a tert-butyl group at the terminal carbon in $76 \%$ yield after quenching with $\mathrm{H}_{2} \mathrm{O}$. The allylated product 55 was obtained in 54\% yield when the reaction mixture was treated with allyl bromide instead of $\mathrm{H}_{2} \mathrm{O}$ (run 7). A vinylsilane also afforded the corresponding product in good yield (run 8). When internal alkenes, 1-octene, and isoprene were used, no reaction took place under similar conditions.

Carbomagnesation of alkenes has long been studied for
Table 4. Ti-Catalyzed carbomagnesation

alkene

${ }^{a}$ Isolated yield. ${ }^{b}$ NMR yield.

more than five decades. The most straightforward method is non-catalyzed intermolecular addition of Grignard reagents to carbon-carbon double bonds, but the reaction usually requires severe conditions and has been applied to only limited substrates ${ }^{30}$. As an attractive alternative to this method, there have been developed several reactions using a transition metal catalyst such as $\mathrm{Ni}^{31 \mathrm{a}}, \mathrm{Cu}^{31 \mathrm{~b}}$, $\mathrm{Ti}^{31 \mathrm{c}}$, and $\mathrm{Zr}^{31 \mathrm{~d}}$ complexes; however, these reactions also lack generality in the scope of usable substrates. The present reaction will be synthetically useful since a variety of alkyl groups can be introduced to alkenes and dienes by using the corresponding alkyl halides.

\section{Double-Silylation of Alkenes and Dienes ${ }^{32}$}

The double-silylation of unsaturated hydrocarbons has extensively been studied using late transition metal catalysts, such as palladium and platinum complexes, and disilanes or hydrosilanes as the silylating reagents ${ }^{1 \mathrm{~b}, 33}$. In this section, we describe the first example of a transition metal-catalyzed double-silylation of dienes and alkenes with chlorosilanes, which proceeds under mild conditions by the use of $\mathrm{Cp}_{2} \mathrm{TiCl}_{2}$ in the presence of ${ }^{\mathrm{n}} \mathrm{BuMgCl}$.

When $p$-chlorostyrene was treated with 2 equivalents of $\mathrm{Et}_{3} \mathrm{SiCl}$ and ${ }^{\mathrm{n}} \mathrm{BuMgCl}$ in the presence of a catalytic amount of titanocene dichloride at $0{ }^{\circ} \mathrm{C}$ in THF, vic-double-silylated product 57 was obtained in $8 \%$ yield (eq 11). Use of $\mathrm{Me}_{2} \mathrm{PhSi}$ $\mathrm{Cl}$ improved the yield of $\mathbf{5 8}$ into $29 \%$, but a substantial amount of $\mathrm{Me}_{2} \mathrm{PhSi}{ }^{\mathrm{n}} \mathrm{Bu}$ was formed. This problem was overcome by using a large amount of catalyst $(15 \mathrm{~mol} \%)$ and by 
adopting a dropwise addition of $\mathrm{Me}_{2} \mathrm{PhSiCl}$ giving rise to $\mathbf{5 8}$ in $76 \%$ yield. The present reaction also may proceed via a benzyl radical intermediate which is formed by the addition of a silyl radical species to styrene. Since the dimethylphenyl silyl radical is more stable than the triethylsilyl radical, the former would be generated more readily from the corresponding chlorosilane by one electron transfer from a titanate complex $\left[\mathrm{Cp}_{2} \mathrm{Ti}^{\mathrm{n}} \mathrm{Bu}_{2}\right]^{-} \mathrm{MgCl}^{+}$affording better yield of the double-silylation product.

Isoprene underwent double-silylation efficiently, giving rise to 1,4-double-silylated products $\mathbf{5 9}$ and $\mathbf{6 0}$ in $78 \%$ and $91 \%$ yields, respectively (eq 12). In contrast to the case of styrene, the reaction of isoprene proceeds efficiently using $\mathrm{Et}_{3} \mathrm{SiCl}$. This may suggest that an alternative mechanism operates in double-silylation of dienes. A possible pathway may involve formation of titanacyclopentenes from $\mathrm{Cp}_{2} \mathrm{Ti}$ and dienes as the intermediates, which then undergo transmetalation by the reaction with ${ }^{\mathrm{n}} \mathrm{BuMgCl}$ as shown in the next section.

$$
\begin{aligned}
& p-\mathrm{ClC}_{6} \mathrm{H}_{4} \downarrow+\mathrm{R}_{3} \mathrm{Si}-\mathrm{Cl} \underset{{ }^{\mathrm{n}} \mathrm{BuMgCl}}{\stackrel{\text { cat. } \mathrm{Cp}_{2} \mathrm{TiCl}_{2}}{\longrightarrow}}
\end{aligned}
$$

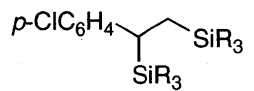

$57\left(\mathrm{R}_{3} \mathrm{Si}=\mathrm{Et}_{3} \mathrm{Si}\right), 8 \%$

$58\left(\mathrm{R}_{3} \mathrm{Si}=\mathrm{Me}_{2} \mathrm{PhSi}\right), 29 \%$ (see text for conditions), $76 \%$

$$
\begin{aligned}
& \underset{+}{d} \mathrm{R}_{3} \mathrm{Si}-\mathrm{Cl} \stackrel{\mathrm{Cp}_{2} \mathrm{TiCl}_{2}(5 \mathrm{~mol} \%)}{{ }^{\mathrm{n}} \mathrm{BuMgCl}} \\
& \mathrm{R}_{3} \mathrm{Si} \bigcup_{\mathrm{SiR}_{3}} \\
& 59\left(\mathrm{R}_{3} \mathrm{Si}=\mathrm{Me}_{2} \mathrm{PhSi}\right), 78 \%[E / Z=69 / 31] \\
& 60\left(\mathrm{R}_{3} \mathrm{Si}=\mathrm{Et}_{3} \mathrm{Si}\right), 91 \%[E / Z=91 / 9]
\end{aligned}
$$

\section{Silylative Coupling of Vinyl Grignard Reagents ${ }^{34}$}

In addition to the regioselective introduction of alkyl and/or silyl functionalities to alkenes and dienes mentioned above, $\mathrm{Cp}_{2} \mathrm{TiCl}_{2} / \mathrm{RMgX}$ catalyzed systems have been applied to the reduction of organohalides ${ }^{35 a}$ and carbonyl compounds $^{35 b}$ or to the hydromagnesation of carbon-carbon unsaturated bonds ${ }^{13}$. In these reactions, however, Grignard reagents have been used as the reducing reagent of titanocene complexes or as the hydrogen source and their carbon moieties have not been incorporated in the products. This section deals with a new type of titanocene-catalyzed coupling reactions in which the organic moieties of Grignard reagents are involved in the products.

When a reaction of $\mathrm{Me}_{2} \mathrm{PhSiCl}$ with vinyl Grignard reagent (1 equiv) was conducted in the presence of a catalytic amount of $\mathrm{Cp}_{2} \mathrm{TiCl}_{2}, 1,4$-bis(dimethylphenylsilyl)-2-butene (61; $\mathrm{R}_{3} \mathrm{Si}=\mathrm{Me}_{2} \mathrm{PhSi}$ ) was obtained in $94 \%$ yield with an $E / Z$ ratio of 74/26 (eq 13). Under the conditions employed, the direct reaction of vinylmagnesium bromide with chlorosilane was slow and only a trace amount of $\mathrm{CH}_{2}=\mathrm{CHSiMe}_{2} \mathrm{Ph}$ $(<1 \%)$ was formed as a byproduct. This reaction also procceds when trialkylsilyl chlorides are used as the silylating reagents, giving rise to $\mathbf{6 2}$ and $\mathbf{6 3}$ in good yields. When dichlorodiphenylsilane was treated with 2 equivalents of vinyl
Grignard reagent at $-20{ }^{\circ} \mathrm{C}$ for $3 \mathrm{~h}$, cyclization predominated to afford 1,1-diphenyl-1-silacyclo-3-pentene 64 in $73 \%$ yield (eq 14).

$$
\begin{aligned}
\mathrm{MgBr}+\mathrm{R}_{3} \mathrm{Si}-\mathrm{Cl} & \stackrel{\mathrm{Cp}_{2} \mathrm{TiCl}_{2}(5 \mathrm{~mol} \%)}{\mathrm{THF}, 0{ }^{\circ} \mathrm{C}, 10 \mathrm{~min}} \\
& 61\left(\mathrm{R}_{3} \mathrm{Si}=\mathrm{Me}_{2} \mathrm{PhSi}\right), 94 \%[E / Z=74 / 26] \\
& \mathbf{6 2}\left(\mathrm{R}_{3} \mathrm{Si}=\mathrm{Et}_{3} \mathrm{Si}\right), 68 \%[E / Z=72 / 28] \\
& \mathbf{6 3}\left(\mathrm{R}_{3} \mathrm{Si}=\mathrm{Me}_{3} \mathrm{Si}\right), 85 \%[E / Z=76 / 24]
\end{aligned}
$$

$$
ح_{\mathrm{MgBr}}+\mathrm{Ph}_{2} \mathrm{SiCl}_{2} \frac{\mathrm{Cp}_{2} \mathrm{TiCl}_{2}(5 \mathrm{~mol} \%)}{\mathrm{THF},-20^{\circ} \mathrm{C}, 3 \mathrm{~h}} \leadsto \mathrm{SiPh}_{2}
$$

$64,73 \%$

A plausible reaction pathway of this silylative vinyl coupling is shown in Scheme 4. Titanocene dichloride reacts with 2 equivalents of $\mathrm{CH}_{2}=\mathrm{CHMgBr}$ to generate divinyltitanocene complex $\mathbf{6 5}$, which readily forms titanocene-butadiene complex 66 or its $s$-trans isomer via reductive coupling ${ }^{36,37}$. Then, $\mathbf{6 6}$ isomerizes to titanacyclopentene $\mathbf{6 7} 7^{38}$. The successive transmetalation of $\mathbf{6 7}$ with vinyl Grignard reagent affords allylmagnesium species $\mathbf{6 8}$, which reacts with a chlorosilane to give allylsilane $\mathbf{6 9}$ carrying a titanocene group on the other allylic position. Subsequent transmetalation of 69 with $\mathrm{CH}_{2}=\mathrm{CHMgBr}$ followed by trapping with a chlorosilane gives the corresponding product along with regeneration of 65 .

Scheme 4

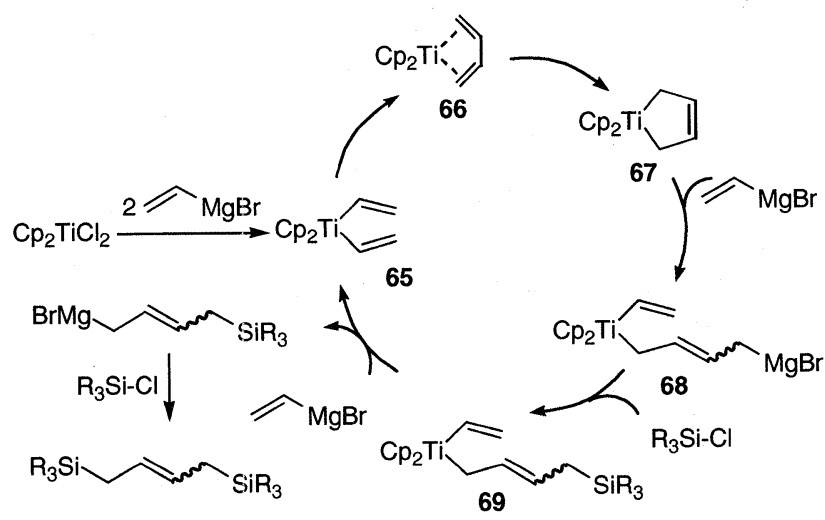

\section{Conclusion}

A novel catalytic system for regioselective alkylation and/or silylation of alkenes or dienes has been developed by the aid of a titanocene complex. These reactions proceed under mild conditions by the use of alkyl halides and/or chlorosilanes in the presence of Grignard reagents. Although alkyl halides and chlorosilanes are the most easily available and widely used substrates in organic syntheses, their use in transition metal catalyzed reactions has been limited. This is probably due to (i) the slow oxidative addition of alkyl halides to metal complexes and the fast $\beta$-hydrogen elimination from $\sigma$-alkylmetal intermediates, and (ii) the difficulty of the oxidative addition of the $\mathrm{Si}-\mathrm{Cl}$ bond to metal complexes. 
The reactions mentioned here are attractive from both mechanistic and synthetic viewpoints. This study will open up a new field of transition metal chemistry providing a unique methodology for introduction of alkyl and silyl groups across carbon-carbon unsaturated units.

Acknowledgement We thank Professor Noboru Sonoda at Kansai University, who is a Professor Emeritus at Osaka University, for his continuous support of this work. Special thanks are given to Dr. Hitoshi Kuniyasu for stimulating discussions and helpful suggestions and also to co-workers $\mathrm{Mr}$. S. Nii, Ms. M. Miyamoto, Mr. H. Watabe, and Mr. K. Saito for their active collaboration in the present work. This research was supported in part by a Grant-in-Aid from the Ministry of Education, Culture, Sports, Science and Technology of Japan. We are also grateful to the Asahi Glass Foundation for financial support.

\section{References}

1) (a) Metal-catalyzed Cross-coupling Reactions; Diederich, F.; Stang, P.J., Eds.; WILEY-VCH: Weinheim, 1997; Chapters 3, 6 and 7. (b) Tsuji, J. Palladium Reagents and Catalysts; John Wiley \& Sons, Inc.: Chichester, 1995. (c) Transition Metals for Organic Synthesis; Beller, M.; Bolm, C., Eds.; WILEY-VCH, Weinheim, 1998; Vol. 1.

2) (a) Ojima, I.; Li, Z.; Zhu, J. In The Chemistry of Organic Silicon Compounds Volume 2; Patai, S.; Rappoport, Z.; Eds.; John Wiley\&Sons: Chichester, 1998; Part 2, pp.1687-1792. (b) Reichel, J. A.; Berry, D. H. In Advances in Organometallic Chemistry; Stone, F. G. A.; West, R., Eds.; Academic Press: New York, 1998; pp.197-265.

3) Terao, J.; Watanabe, T.; Saito, K.; Kambe, N.; Sonoda, N. Tetrahedron Lett. 1998, 39, 9201.

4) Terao, J.; Torii, K.; Saito, K.; Kambe, N.; Baba, A.; Sonoda, N. Angew. Chem., Int. Ed. 1998, 37, 2653.

5) Tatsumi, K. In Kikan Kagaku Sousetu No. 17, Organic Chemistry of the Early Ttransition Metals; Gakkai Shuppan Center: Tokyo, 1993, pp.1-20.

6) For a recent review on synthetic application of $\mathrm{Cp}_{2} \mathrm{TiCl}_{2}$, see: Petasis, N. A.; Hu, Y. -H.; Current Organic Chemistry 1997, 1, 249.

7) Terao, J.; Saito, K.; Nii, S.; Kambe, N.; Sonoda, N. J. Am. Chem. Soc. 1998, 120, 11822.

8) For the formation of $\mathrm{Cp}_{2} \mathrm{TiCl}$ from $\mathrm{Cp}_{2} \mathrm{TiCl}_{2}$ in the presence of alkyl Grignard reagents, see: Martin, H. A.; Jellinek, F. $J$. Organomet. Chem. 1968, 12, 149.

9) Reaction of $\mathrm{Cp}_{2} \mathrm{TiCl}$ with ${ }^{\mathrm{n}} \mathrm{BuLi}$ affords the thermally unstable 12, see: Klei, E.; Telgen, J. H.; Teuben, J. H. J. Organomet. Chem. 1981, 209, 297.

10) It is known that alkyl radicals are generated in the titanocenecatalyzed reduction of alkyl bromides with ${ }^{\mathrm{i}} \mathrm{PrMgBr}$. Rilatt, J. A.; Kitching, W. Organometallics 1982, 1, 1089.

11) It is reported that $14 \mathrm{a}$ decomposes rapidly at $-50{ }^{\circ} \mathrm{C}$ forming 15 along with a 1:1 mixture of $n$-butane and butenes. McDermott, J. X.; Wilson, M. E.; Whitesides, G. M. J. Am. Chem. Soc. 1976, 98, 6529 .

12) Transmetalation of vinyltitanocene complexes with ${ }^{\mathrm{P}} \mathrm{PrMgBr}$ is known. Gao, Y.; Sato, F. J. Chem. Soc., Chem. Commun. 1995, 659.

13) Sato, F. J. Organomet. Chem. 1985, 285, 53. Gao, Y.; Sato, F. J. Chem. Soc., Chem. Commun. 1995, 659. and references therein.

14) Colomer, E.; Corriu, R. J. Organomet. Chem. 1974, 82, 367.

15) (a) Brintzinger, H. H. J. Am. Chem. Soc. 1967, 89, 6871-6877. (b) Troyanov, S. I.; Varga, V.; Mach, K. J. Organomet. Chem. 1993, 461, 85 .

16) Maillard, B.; Forrest, D.; Ingold, K. U. J. Am. Chem. Soc. 1976, 98, 7024

17) The rate constant for the addition of 5-hexenyl radical to styrene has been reported: Citterio, A.; Minisci, F. J. Org. Chem. 1979, 44, 2674.

18) Prepared following a literature description: Harvey, S.; Junk, P. C.; Raston, C. L.; Salem, G. J. Org. Chem. 1988, 53, 3134

19) Reactivities of Grignard reagents toward alkyl bromides largely depend on the structures of the Grignard reagents. For example, $\mathrm{PhCH}_{2} \mathrm{MgCl}(1.09 \mathrm{M})$ reacted with ${ }^{i} \mathrm{PrBr}$ (1.5 equiv) much slower giving iso-butylbenzene in only $8 \%$ at $0{ }^{\circ} \mathrm{C}$ for $1 \mathrm{~h}$, and ${ }^{n} \mathrm{BuMg}$ $\mathrm{Cl}$ was not alkylated by ${ }^{\mathrm{i}} \mathrm{PrBr}$ under the same conditions.

20) Terao, J.; Miyamoto, M.; Kambe, N. Result to be submitted for publication

21) Mizoroki, T.; Mori, K.; Ozaki, A. Bull. Chem. Soc. Jpn. 1971, 44, 581. Heck, R. F.; Nolley, J. P. J. Org. Chem. 1972, 37, 2320.

22) Recently it was reported that the palladium-catalyzed reaction of 1-bromoadamantane with styrenes gave the corresponding Heck-type coupling products in $15-41 \%$ yields: Brase, S.; Waegell, B.; Meijere, A. Synthesis 1998, 148.

23) (a) Lebedev, S. A.; Lopatina, V. S.; Shifrana, R. R.; Petrov, E. S.; Beletskaya, I. P. Izv. Akad. Nauk SSSR 1983, 10, 2414. Lebedev, S. A.; Lopatina, V. S.; Luk'yanova, T. V.; Berestova, S. S.; Shifrana, R. R.; Shapet'ko, N. N.; Petrov, E. S.; Beletskaya, I. P. Izv. Akad. Nauk SSSR 1985, 22, 652. (b) Branchaud, B. P.; Detlefsen, W. D. Tetrahedron Lett. 1991, 32, 6273.

24) Nii, S.; Terao, J.; Kambe, N. J. Org. Chem. 2000, 65, 5291.

25) Lewis acid-catalyzed addition of allylsilane: Asao, N.; Yoshikawa, E.; Yamamoto, Y. J. Org. Chem. 1996, 61, 4874. Pd-catalyzed carbosilylation; Chatani, N.; Hanafusa, T. $J$. Chem. Soc., Chem. Commun., 1985, 838. Sakurai, H.; Kamiyama, Y.; Nakadaira, Y. J. Am. Chem. Soc. 1977, 99, 3879. Saso, H.; Ando, W. Chem. Lett. 1988, 1567. Sakurai, H.; Imai, T. Chem. Lett. 1975, 891. Chatani, N.; Amishiro, N.; Murai, S. J. Am. Chem. Soc. 1991, 113, 7778. Chatani, N.; Amishiro, N.; Morii, T.; Yamashita, T.; Murai, S. J. Org. Chem. 1995, 60, 1834.

26) Obora, Y.; Tsuji, Y.; Kawamura, T. J. Am. Chem. Soc. 1995, $117,9814$.

27) Wu, M.; Yang, F.; Cheng, C. J. Org. Chem. 1999, 64, 2471.

28) Martin, H. A.; Jellinek, F. Angew. Chem. 1964, 76, 274. Chen, J.; Kai, Y.; Kasai, N.; Yasuda, H.; Yamamoto, H.; Nakamura. J. Organomet. Chem. 1991, 407, 191.

29) Nii, S.; Terao, J.; Kambe, N. Result to be submitted for publication.

30) Wakefield, B. J. In Organomagnesium Methods in Organic Synthesis; Wakefield, B. J. Ed.; Academic Press INC: San Diego, 1995, Chapter 4

31) (a) Duboudin, J. -G.; Jousseaume, B. J. Organomet. Chem. 1972, 44, C1-C3. Snider, B. B.; Karras, M.; Conn, R. S. E. J Am. Chem. Soc. 1978, 100, 4624. Snider, B. B.; Conn, R. S. E Karras, M. Tetrahedron Lett. 1979, 19, 1679. (b) Duboudin, J -G.; Jousseaume, B.; Bonakdar, A. J. Organomet. Chem. 1979 , 168, 227. (c) Akutagawa, S.; Otsuka, S. J. Am. Chem. Soc. 1975, 97, 6870. (d) Dzhemilev, U. M.; Vostrikova O. S. and Sultanov, R. M. Izv. Akad. Nauk SSSR, Ser. Khim. 1983, 218. Fischer, R.; Walther, D.; Gebhardt, P.; Gorls, H. Organometallics 2000, 19, 2532 and references cited therein.

32) Terao, J.; Kambe, N.; Sonoda, N. Tetrahedron Lett. 1998, 39, 9697.

33) For reviews, see: Horn, K. A. Chem. Rev. 1995, 95, 1317. See, also: Sakaki, S.; Ogawa, M.; Musashi, Y. J. Organomet. Chem. 1997, 535, 25-28 and references cited therein.

34) Watabe, H.; Terao, J.; Kambe, N. Org. Lett. 2001, 3, 1733.

35) (a) Colomer, E.; Corriu, R. J. Organomet. Chem. 1974, 82, 367. Rilatt, J. A.; Kitching, W. Organometallics 1982, 1, 1089. Hara, R; Sato, K.; Sun, W. H.; Takahashi, T. Chem. Commun, 1999, 845. Corriu, R. J. P.; Meunier, B. J. Organomet. Chem. 1974 65, 187. (b) Sato, F.; Jinbo, T.; Sato, M. Tetrahedron Lett. 1980, 21, 2171. Sato, F.; Jinbo, T.; Sato, M. Tetrahedron Lett. 1980, 21, 2175. Sato, F.; Jinbo, T.; Sato, M. Synthesis 1981, 871.

36) (a) Beckhaus, R.; Thiele, K. -H. J. Organomet. Chem. 1986, 317, 23. (b) Beckhaus, R.; Flatau, S.; Trojanov, S.; Hofmann, P. Chem. Ber. 1992, 125, 291. (c) Beckhaus, R. Angew. Chem., Int. Ed. Engl. 1997, 36, 686.

37) Similar reaction has also been reported for zirconocene, i.e., $\mathrm{Cp}_{2} \mathrm{ZrCl}_{2}$ reacts with $\mathrm{CH}_{2}=\mathrm{CHLi}$ to form $\mathrm{Cp}_{2} \mathrm{Zr}\left(\mathrm{CH}=\mathrm{CH}_{2}\right)_{2}$ which undergoes reductive coupling to afford butadiene; Beckhaus, R.; Thiele, K. -H. J. Organomet. Chem. 1984, 268, C7-C8.

38) Isomerization of zirconocene-butadiene complex to zirconacyclopentene is known, see: (a) Erker, G.; Wicher, J.; Engel, K.; Rosenfeldt, F.; Dietrich, W.; Krüger, C. J. Am. Chem. Soc. 1980, 102, 6344. (b) Yasuda, H.; Nakamura, A. Angew. Chem., Int. Ed. Engl. 1987, 26, 723 . 
Jun Terao is an Assistant Professor of Osaka University. He received his B. Sc (1994) and $\mathrm{Ph}$. D. degree (1999) from Osaka University. After working as a postdoctoral fellow at Hokkaido University under Professor Tamotsu Takahashi, he joined the Department of Applied Chemistry, Osaka University, as an Assistant Professor. In 2001, he received the Bauyu Pharmaceutical Award in Synthetic Organic Chemistry, Japan. His research interests are in the areas of organometallic chemistry and synthetic organic chemistry.

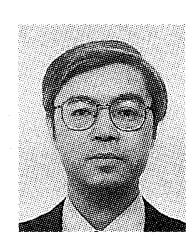

Nobuaki Kambe is Professor of organic chemistry at Osaka University. He studied chemistry and received his $\mathrm{Ph}$. D. degree (1981) from Osaka University. He joined the Department of Applied Chemistry, Faculty of Engineering, Osaka University in 1981 as an Assistant Professor. He was promoted to Associate Professor in 1989 and to Professor in 1999. He received the Chemical Society of Japan Award for Young Chemists in 1988 and the Japan Petroleum Institute Award for Encouragement of Research and Development in 1993. He worked at Colorado State University with Professor L. S. Hegedus as a postdoctoral fellow from 1982 to 1984. His research interests are in the areas of synthetic organic chemistry, organometallic chemistry, and physical organic chemistry. 